\title{
Complete genome sequence of Saccharomonospora viridis type strain $\left(\mathrm{P}^{101}{ }^{\mathrm{T}}\right)$
}

\author{
Amrita Pati ${ }^{1}$, Johannes Sikorski ${ }^{2}$, Matt Nolan' ${ }^{1}$, Alla Lapidus ${ }^{1}$, Alex Copeland', Tijana Glavina \\ Del Rio" ${ }^{1}$, Susan Lucas ${ }^{1}$, Feng Chen ${ }^{1}$, Hope Tice ${ }^{1}$, Sam Pitluck ${ }^{1}$, Jan-Fang Cheng1 , Olga Chert- \\ kov $^{1,3}$, Thomas Brettin ${ }^{1,3}$, Cliff Han ${ }^{1,3}$, John C. Detter ${ }^{1,3}$, Cheryl Kuske ${ }^{1,3}$, David Bruce ${ }^{1,3}$, \\ Lynne Goodwin ${ }^{1,3}$, Patrick Chain ${ }^{1,4}$, Patrik D'haeseleer ${ }^{1,4}$, Amy Chen ${ }^{5}$, Krishna Palaniappan ${ }^{5}$, \\ Natalia Ivanova ${ }^{1}$, Konstantinos Mavromatis' ${ }^{1}, N^{2}$ alia Mikhailova ${ }^{1}$, Manfred Rohde ${ }^{6}$, Brian J. \\ Tindall $^{2}$, Markus Göker ${ }^{2}$, Jim Bristow ${ }^{1}$, Jonathan A. Eisen ${ }^{1,7}$, Victor Markowitz ${ }^{4}$, Philip Hu- \\ genholtz $^{1}$, Nikos C. Kyrpides ${ }^{1}$, and Hans-Peter Klenk ${ }^{2 *}$ \\ ${ }^{1}$ DOE Joint Genome Institute, Walnut Creek, California, USA \\ ${ }^{2}$ DSMZ - German Collection of Microorganisms and Cell Cultures GmbH, Braunschweig, \\ Germany \\ ${ }^{3}$ Los Alamos National Laboratory, Bioscience Division, Los Alamos, New Mexico, USA \\ ${ }^{4}$ Lawrence Livermore National Laboratory, Livermore, California, USA \\ ${ }^{5}$ Biological Data Management and Technology Center, Lawrence Berkeley National Labora- \\ tory, Berkeley, California, USA \\ ${ }^{6} \mathrm{HZI}$ - Helmholtz Centre for Infection Research, Braunschweig, Germany \\ ${ }^{7}$ University of California Davis Genome Center, Davis, California, USA
}

*Corresponding author: Hans-Peter Klenk

Keywords: thermophile, hot compost, Gram-negative actinomycete, farmer's lung disease, bagassosis, humidifier fever, pentachlorophenol metabolism, Pseudonocardiaceae

\begin{abstract}
Saccharomonospora viridis (Schuurmans et al. 1956) Nonomurea and Ohara 1971 is the type species of the genus Saccharomonospora which belongs to the family Pseudonocardiaceae. S. viridis is of interest because it is a Gram-negative organism classified among the usually Gram-positive actinomycetes. Members of the species are frequently found in hot compost and hay, and its spores can cause farmer's lung disease, bagassosis, and humidifier fever. Strains of the species $S$. viridis have been found to metabolize the xenobiotic pentachlorophenol (PCP). The strain described in this study has been isolated from peat-bog in Ireland. Here we describe the features of this organism, together with the complete genome sequence, and annotation. This is the first complete genome sequence of the family Pseudonocardiaceae, and the 4,308,349 bp long single replicon genome with its 3906 protein-coding and 64 RNA genes is part of the Genomic Encyclopedia of Bacteria and Archaea project.
\end{abstract}

\section{Introduction}

Strain P101 ${ }^{\mathrm{T}}(=\mathrm{DSM} 43017=$ ATCC $15386=\mathrm{JCM}$ $3036=$ NCIMB 9602) is the type strain of Saccharomonospora viridis, and the type species of the genus Saccharomonospora [1,2], which currently contains eight species [3]. Although phylogenetically a member of the Gram-positive actinomycetes, already the initial report on $S$. viridis strain $\mathrm{P} 101^{\mathrm{T}}$ noticed the astonishing feature of the organism to be Gram-negative, despite showing the typical mycelium morphology of Saccharomonospora [2]. Like in other actinomycetes, spores of $S$. viridis are readily dispersed in air, and the prolonged exposure to spores can apparently result in acute respiratory distress (farmer's lung disease) which may lead to irreversible lung damage $[4,5]$. Here we present a summary classification and a set of features for $S$. viridis $\mathrm{P} 101^{\mathrm{T}}$, together with the description of the complete genomic sequencing and annotation.

\section{Classification and features}

Members of the species $S$. viridis have been isolated or molecularly identified on several occasions from hot composts in Europe and USA [1214,17], and also from soil in Japan [1]. One novel, yet unpublished, cultivated member of the species 
has been reported by Lu and Liu from Chinese soil (AF127525). Uncultured clone sequences with significant (99\%) sequence similarity were observed from composting mass in China (AM930281 and AM930338). Screening of environmental genomic samples and surveys reported at the NCBI BLAST server indicated no closely related phylotypes that can be linked to the species or genus, with the closest matches (about 90\% sequence similarity) to strain $\mathrm{P} 101^{\mathrm{T}} 16 \mathrm{~S}$ rRNA identified in a marine metagenome from the Sargasso Sea [18].

Figure 1 shows the phylogenetic neighborhood of $S$. viridis strain $\mathrm{P} 101^{\mathrm{T}}$ in a $16 \mathrm{~S}$ rRNA based tree. The sequences of all three copies of the 16S rRNA gene are identical and perfectly match the previously published 16S rRNA sequence generated from NCIMB 9602 (Z38007).

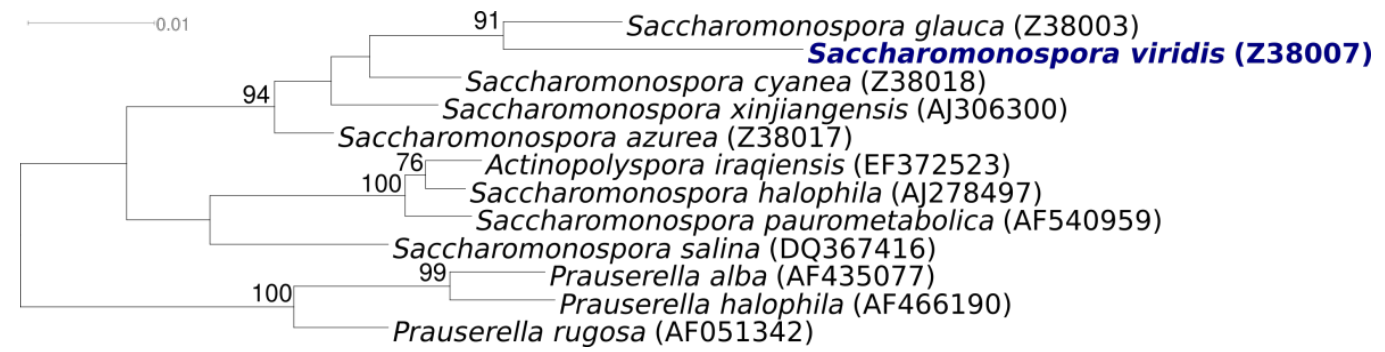

Figure 1. Phylogenetic tree of $S$. viridis strain $\mathrm{P} 101^{\top}$ and all type strains of the genus Saccharomonospora inferred from 1,474 aligned characters [19,20] of the 16S rRNA gene under the maximum likelihood criterion [21]. The tree was rooted with all type strains of the members of the genus Prauserella, another genus in the family Pseudonocardiaceae. The branches are scaled in terms of the expected number of substitutions per site. Numbers above branches are support values from 1,000 bootstrap replicates if larger than $60 \%$. Lineages with type strain genome sequencing projects registered in GOLD [22] are shown in blue, published genomes in bold.

The hyphae of the vegetative mycelium of strain $\mathrm{P} 101^{\mathrm{T}}$ are branched and sometimes show curved endings [12]. Single spores are observed only on the aerial mycelium either directly on the hyphae or on short sporophores (Table 1 and Figure 2). The spores are oval, $0.9-1.1 \mu \mathrm{m} \times 1.2-1.4 \mu \mathrm{m}$ in size. Only very occasionally two spores are observed. The aerial mycelium is either grayish green in color, or turns from white to greenish as on Czapek Agar. The optimal temperature for growth is $55^{\circ} \mathrm{C}$, but $45^{\circ} \mathrm{C}$ for aerial mycelium formation and pigment production. At $37^{\circ} \mathrm{C}$ and $60^{\circ} \mathrm{C}$ the growth is very limited and without aerial mycelia. No growth occurs at $27^{\circ} \mathrm{C}$ and $70^{\circ} \mathrm{C}[12]$.

Strain $\mathrm{P} 101^{\mathrm{T}}$ has been observed to be sensitive to a variety of phages [11]. Members of $S$. viridis are apparently able to metabolize pentachlorophenol but not other chlorophenols [14]. It was suggested that $S$. viridis metabolizes PCP by conjugation to form a more polar transformation product, but, unlike other PCP-degrading bacteria, the organism is incapable of effecting total degradation of the xenobiotic [14]. Microorganisms such as S. viridis may therefore contribute to PCP removal by microbial communities in situ, despite being unable to completely mineralize chlorophenols in pure culture [14]. S. viridis produces a thermostable $\alpha$ amylase which forms $63 \%(\mathrm{w} / \mathrm{w})$ maltose on hydrolysis of starch [23]. Maltotriose and maltotetraose are the only intermediate products observed during this reaction, with maltotriose accumulating to $40 \%(\mathrm{w} / \mathrm{w})$. Both unimolecular and multimolecular mechanisms (transfers and condensation) have been shown to occur during the concentration-dependent degradation of maltotriose and maltotetraose. Such reactions result in the almost exclusive formation of maltose from maltotriose at high initial concentration [23]. S. viridis produces thermoviridin, an antibiotic that is primarily active against the Gram-positive bacteria (growth inhibition) [2,11]. At higher concentrations, also Gram-negative bacteria were growthinhibited [2].

\section{Chemotaxonomy}

The murein of $\mathrm{P} 101^{\mathrm{T}}$ is of cell wall type IV. It contains meso-diaminopimelic acid in the peptidoglycan and arabinose and galactose in whole-cell hydrolysates (sugar type A). Mycolic acids and teichonic acids were not reported. Strain P101T con- 
Pati, et al.

tains menaquinones MK-9 $\left(\mathrm{H}_{4}\right)(60 \%)$ and MK$8\left(\mathrm{H}_{4}\right)$ (20 to $\left.30 \%\right)$. The combination of the tetrahydromultiprenyl menaquinones $\mathrm{MK}-9\left(\mathrm{H}_{4}\right)$ and MK-8 $\left(\mathrm{H}_{4}\right)$ is characteristic for the genus Saccharomonospora [11]. The major cellular fatty acids are saturated, iso-branched acids with 16 and 18 carbon atoms, and 2-hydroxydodecanoic acids. Details are described in the Compendium of Actinobacteria [10]. Phosphatidylethanolamine, hydroxy-phosphatidyl-ethanolamine, and lyso-phosphatidyl-ethanolamine were identified as the main phospholipids.

Table 1. Classification and general features of $S$. viridis $\mathrm{P} 101^{\top}$ according to the MIGS recommendations [6]

\begin{tabular}{|c|c|c|c|}
\hline MIGS ID & Property & Term & $\begin{array}{l}\text { Evidence } \\
\text { code }\end{array}$ \\
\hline & \multirow{8}{*}{ Current classification } & Domain Bacteria & TAS [7] \\
\hline & & Phylum Actinobacteria & TAS [8] \\
\hline & & Order Actinomycetales & TAS [9] \\
\hline & & Suborder Pseudonocardineae & TAS [9] \\
\hline & & Family Pseudonocardiaceae & TAS [9] \\
\hline & & Genus Saccharomonospora & TAS [1] \\
\hline & & Species Saccharomonospora viridis & TAS [2] \\
\hline & & Type strain P101 & \\
\hline & Gram stain & negative & TAS [2] \\
\hline & Cell shape & variable & TAS [10] \\
\hline & Motility & $\begin{array}{l}\text { nonmotile } \\
\text { single spores mainly on aerial myce- }\end{array}$ & NAS \\
\hline & Sporulation & lium & TAS [1] \\
\hline & Temperature range & thermophile, $37-60^{\circ} \mathrm{C}$ & TAS [11] \\
\hline & Optimum temperature & $\begin{array}{l}55^{\circ} \mathrm{C} \text { for growth, } 45^{\circ} \mathrm{C} \text { for aerial my- } \\
\text { celium formation }\end{array}$ & $\begin{array}{l}\text { TAS } \\
{[1,11,12]}\end{array}$ \\
\hline \multirow{4}{*}{ MIGS-22 } & Salinity & $7 \% \mathrm{NaCl}$ & TAS [11] \\
\hline & Oxygen requirement & aerobic; nor reported if essential & TAS [11] \\
\hline & Carbon source & D-glucose, sucrose, dextrin & TAS [11] \\
\hline & Energy source & $\begin{array}{l}\text { carbohydrates } \\
\text { peat and compost (species occur- }\end{array}$ & $\begin{array}{l}\text { TAS }[11] \\
\text { TAS }\end{array}$ \\
\hline MIGS-6 & Habitat & rence) & {$[1,4,12-14]$} \\
\hline MIGS-15 & Biotic relationship & free living & \\
\hline \multirow[t]{3}{*}{ MIGS-14 } & Pathogenicity & lung damage & TAS [4] \\
\hline & Biosafety level & 1 & TAS [15] \\
\hline & Isolation & peat-bog at $250 \mathrm{~cm}$ depth & TAS [12] \\
\hline MIGS-4 & $\begin{array}{l}\text { Geographic location } \\
\text { Sample collection }\end{array}$ & Irish peat & \\
\hline $\begin{array}{l}\text { MIGS-5 } \\
\text { MIGS-4.1 }\end{array}$ & time & before 1963 & TAS [12] \\
\hline MIGS-4.2 & Latitude - Longitude & not reported & \\
\hline MIGS-4.3 & Depth & not reported & \\
\hline MIGS-4.4 & Altitude & not reported & \\
\hline
\end{tabular}

Evidence codes - IDA: Inferred from Direct Assay (first time in publication); TAS: Traceable Author Statement (i.e., a direct report exists in the literature); NAS: Non-traceable Author Statement (i.e., not directly observed for the living, isolated sample, but based on a generally accepted property for the species, or anecdotal evidence). These evidence codes are from the Gene Ontology project [16]. If the evidence code is IDA, then the property was observed for a living isolate by one of the authors, or an expert mentioned in the acknowledgements. 


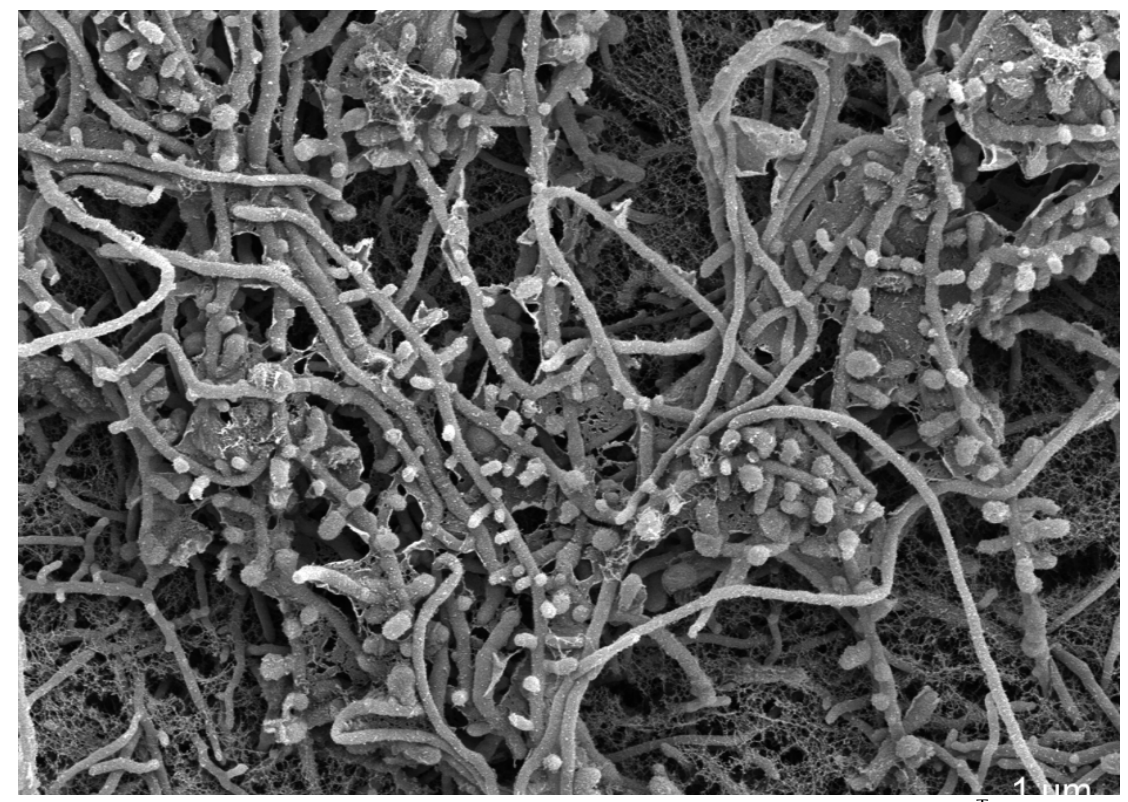

Figure 2. Scanning electron micrograph of S. viridis P101

\section{Genome sequencing and annotation- Genome project history}

This organispm was selected for sequencing on the basis of its phylogenetic position, and is part of the Genomic Encyclopedia of Bacteria and Archaea project. The genome project is deposited in the Genome OnLine Database [22] and the complete genome sequence in GenBank. Sequencing, finishing and annotation were performed by the DOE
Joint Genome Institute (JGI). A summary of the project information is shown in Table 2.

\section{Growth conditions and DNA isolation}

S. viridis strain $\mathrm{P} 101^{\mathrm{T}}$, DSM 43017, was grown in DSMZ medium 535 (Trypticase soy broth, ) at $45^{\circ} \mathrm{C}$. DNA was isolated from 1-1.5 g of cell paste using Qiagen Genomic 500 DNA Kit (Qiagen, Hilden, Germany) with a modified protocol, st/FT, for cell lysis, as described in Wu et al. [24].

Table 2. Genome sequencing project information

\begin{tabular}{lll}
\hline MIGS ID & Property & Term \\
\hline MIGS-31 & Finishing quality & Finished \\
MIGS-28 & Libraries used & Two Sanger libraries - 8 kb pMCL200 \\
MIGS-29 & and fosmid pcc1Fos \\
MIGS-31.2 & Sequencing platforms & ABI3730 \\
MIGS-30 & Assemblers & $12.9 \times$ Sanger \\
MIGS-32 & Gene calling method & Genemark 4.6b, tRNAScan-SE-1.23, \\
& INSDC / Genbank ID & infernal 0.81, GenePRIMP \\
& Genbank Date of Release & August 26, 2009 \\
& GOLD ID & Gc01088 \\
& NCBI project ID & 20835 \\
& Database: IMG-GEBA & 2500901760 \\
MIGS-13 & Source material identifier & DSM 43017 \\
& Project relevance & Tree of Life, GEBA \\
\hline
\end{tabular}

\section{Genome sequencing and assembly}

The genome was sequenced using Sanger sequencing platform only. All general aspects of li- brary construction and sequencing can be found at the JGI website (http://www.jgi.doe.gov). The 
Pati, et al.

Phred/Phrap/Consed software package was used for sequence assembly and quality assessment. After the shotgun stage reads were assembled with parallel phrap (High Performance Software, LLC). Possible mis-assemblies were corrected with Dupfinisher [25] or transposon bombing of bridging clones (Epicentre Biotechnologies, Madison, WI). Gaps between contigs were closed by editing in Consed, custom primer walk or PCR amplification (Roche Applied Science, Indianapolis, IN). A total of 354 finishing reactions were produced to close gaps and to raise the quality of the finished sequence. The completed genome sequences of $S$. viridis contains 66,210 Sanger reads, achieving an average of $12.9 \times$ sequence coverage per base, with an error rate less than 1 in 100,000.

\section{Genome annotation}

Genes were identified using GeneMark [26] as part of the genome annotation pipeline in the Integrated Microbial Genomes Expert Review (IMG-ER) system [27], followed by a round of manual curation using the JGI GenePRIMP pipeline (http://geneprimp.jgi-psf.org) [28]. The predicted CDSs were translated and used to search the National Center for Biotechnology Information (NCBI) nonredundant database, UniProt, TIGRFam, Pfam, PRIAM, KEGG, COG, and InterPro databases. The tRNAScanSE tool [29] was used to find tRNA genes, whereas ribosomal RNAs were found by using the tool RNAmmer [30]. Other non coding RNAs were identified by searching the genome for the Rfam profiles using INFERNAL (v0.81) [31]. Additional gene prediction analysis and manual functional annotation was performed within the Integrated Microbial Genomes (IMG) platform [32].

\section{Metabolic network analysis}

The metabolic Pathway/Genome Database (PGDB) was computationally generated using Pathway Tools software version 12.5 [33] and MetaCyc version 12.5 [34], based on annotated EC numbers and a customized enzyme name mapping file. It has undergone no subsequent manual curation and may contain errors, similar to a Tier 3 BioCyc PGDB [35].

\section{Genome properties}

The genome is 4,308,349 bp long and comprises one main circular chromosome with a $67.3 \%$ GC content (Table 3 and Figure 3). Of the 3,970 genes predicted, 3,906 were protein coding genes, and 64 RNAs; 78 pseudogenes were also identified. The majority of the protein-coding genes (71.2\%) were assigned with a putative function, while the remaining ones were annotated as having hypothetical function. The properties and the statistics of the genome are summarized in Table 3. The distribution of genes into COGs functional categories is presented in Table 4 and a cellular overview diagram is presented in Figure 4, followed by a summary of metabolic network statistics shown in Table 5.

Table 3. Genome Statistics

\begin{tabular}{lrr}
\hline Attribute & \multicolumn{1}{c}{ Value } & \% of Total \\
\hline Genome size (bp) & $4,308,349$ & $100.00 \%$ \\
DNA Coding region (bp) & $3,805,483$ & $88.33 \%$ \\
DNA G+C content (bp) & $2,900,171$ & $67.32 \%$ \\
Number of replicons & 1 & \\
Extrachromosomal elements & 0 & \\
Total genes & 3,970 & $100 \%$ \\
RNA genes & 64 & $1.61 \%$ \\
rRNA operons & 3 & \\
Protein-coding genes & 3,906 & $98.39 \%$ \\
Pseudo genes & 78 & $1.96 \%$ \\
Genes with function prediction & 2,828 & $71.23 \%$ \\
Genes in paralog clusters & 534 & $13.45 \%$ \\
Genes assigned to COGs & 2,709 & $68.24 \%$ \\
Genes assigned Pfam domains & 2,845 & $71.66 \%$ \\
Genes with signal peptides & 725 & $18.26 \%$ \\
Genes with transmembrane helices & 880 & $22.17 \%$ \\
CRISPR repeats & 9 & \\
\hline
\end{tabular}




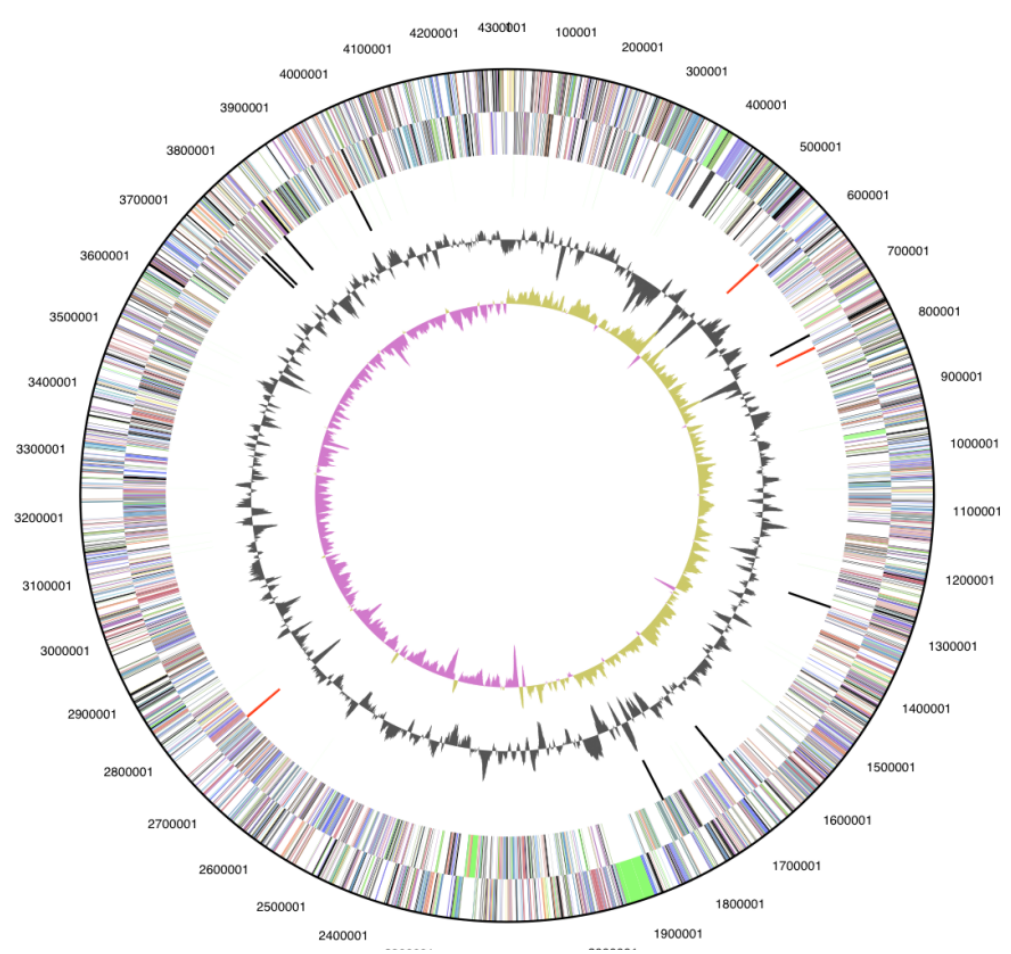

Figure 3. Graphical circular map of the genome. From outside to the center: Genes on forward strand (color by COG categories), Genes on reverse strand (color by COG categories), RNA genes (tRNAs green, rRNAs red, other RNAs black), GC content, GC skew.

Table 4. Number of genes associated with the general COG functional categories

\begin{tabular}{lrrl}
\hline Code & Value & $\%$ & Description \\
\hline J & 158 & 4.0 & Translation, ribosomal structure and biogenesis \\
A & 1 & 0.0 & RNA processing and modification \\
K & 276 & 7.1 & Transcription \\
L & 125 & 3.2 & Replication, recombination and repair \\
B & 1 & 0.0 & Chromatin structure and dynamics \\
D & 25 & 0.6 & Cell cycle control, mitosis and meiosis \\
Y & 0 & 0.0 & Nuclear structure \\
V & 44 & 1.1 & Defense mechanisms \\
T & 146 & 3.7 & Signal transduction mechanisms \\
M & 125 & 3.2 & Cell wall/membrane biogenesis \\
N & 2 & 0.1 & Cell motility \\
Z & 0 & 0.0 & Cytoskeleton \\
W & 0 & 0.0 & Extracellular structures \\
U & 27 & 0.7 & Intracellular trafficking and secretion \\
O & 107 & 2.7 & Posttranslational modification, protein turnover, chaperones \\
C & 214 & 5.5 & Energy production and conversion \\
G & 214 & 5.5 & Carbohydrate transport and metabolism \\
E & 293 & 7.5 & Amino acid transport and metabolism \\
F & 85 & 2.2 & Nucleotide transport and metabolism \\
H & 175 & 4.5 & Coenzyme transport and metabolism \\
\hline
\end{tabular}


Table 4. Number of genes associated with the general COG functional categories

\begin{tabular}{lrrl}
\hline Code & \multicolumn{1}{c}{ Value } & \multicolumn{1}{l}{$\%$} & Description \\
\hline I & 189 & 4.8 & Lipid transport and metabolism \\
P & 146 & 3.7 & Inorganic ion transport and metabolism \\
Q & 139 & 3.6 & Secondary metabolites biosynthesis, transport and catabolism \\
$\mathrm{R}$ & 389 & 10.0 & General function prediction only \\
$\mathrm{S}$ & 182 & 4.7 & Function unknown \\
- & 1197 & 30.6 & Not in COGs \\
\hline
\end{tabular}

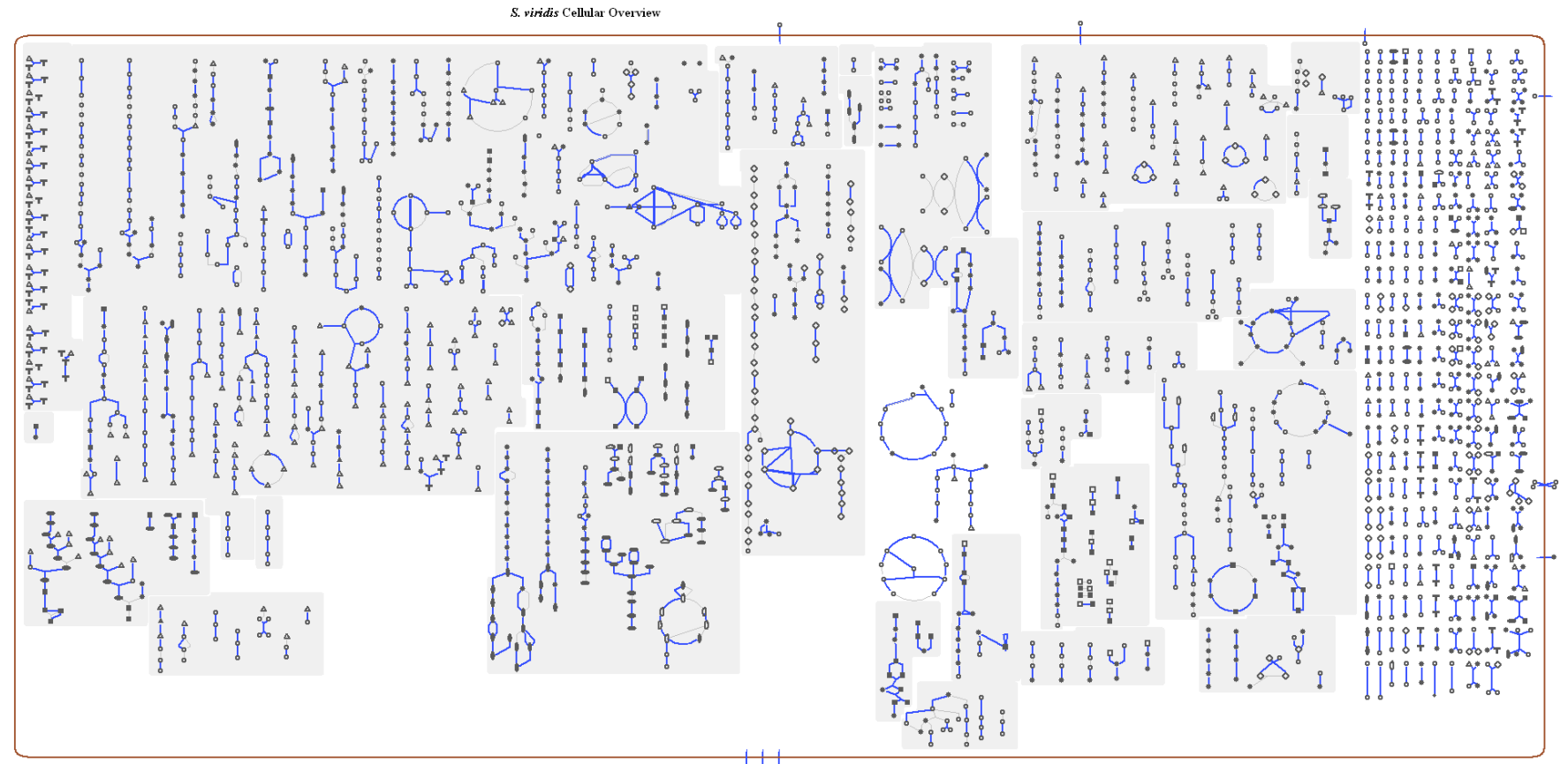

Figure 4. Cellular overview diagram. This diagram provides a schematic of all pathways of $S$. viridis strain $\mathrm{P} 101^{\top}$ metabolism. Nodes represent metabolites, with shape indicating class of metabolite (see key to right). Lines represent reactions.

Table 5. Metabolic Network Statistics

\begin{tabular}{lr}
\hline Attribute & \multicolumn{1}{c}{ Value } \\
\hline Total genes & 3,970 \\
Enzymes & 880 \\
Enzymatic reactions & 1,155 \\
Metabolic pathways & 244 \\
Metabolites & 863 \\
\hline
\end{tabular}

\section{Acknowledgements}

We would like to gratefully acknowledge the help of Marlen Jando for growing S. viridis cultures and Susanne Schneider for DNA extraction and quality analysis (both at DSMZ). This work was performed under the auspices of the US Department of Energy Office of Science, Biological and Environmental Research Program, and by the University of California, Lawrence
Berkeley National Laboratory under contract No. DEAC02-05CH11231, Lawrence Livermore National Laboratory under Contract No. DE-AC52-07NA27344, and Los Alamos National Laboratory under contract No. DEAC02-06NA25396, as well as German Research Foundation (DFG) INST 599/1-1 and SI 1352/1-1. 


\section{References}

1. Nonomura H, Ohara Y. Distribution of Actinomycetes in soil. (X) New genus and species of monosporic actinomycetes. J Ferment Technol 1971; 49:895-903.

2. Schuurmans DM, Olson BH, San Clemente CL. Production and isolation of thermoviridin, an antibiotic produced by Thermoactinomyces viridis $\mathrm{n}$. sp. Appl Environ Microbiol 1956; 4:61-66.

3. Euzéby JP. List of bacterial names with standing in nomenclature: a folder available on the internet. Int J Syst Bacteriol 1997; 47:590-592. PubMed

4. Amner W, Edwards C, McCarthy AJ. Improved medium for recovery and enumeration of the farmer's lung organism, Saccharomonospora viridis. Appl Environ Microbiol 1989; 55:2669-2674. PubMed

5. Roussel S, Reboux G, Dalphin JC, Pernet D, Laplante JJ, Millon L, Piarroux R. Farmer's Lung Disease and Microbiological Composition of Hay: A Case Control Study. Mycopathologia 2005; 160:273-279. PubMed doi:10.1007/s11046-005$\underline{0155-6}$

6. Field D, Garrity G, Gray T, Morrison N, Selengut J, Sterk P, Tatusova T, Thompson N, Allen MJ, Angiuoli SV, et al. Towards a richer description of our complete collection of genomes and metagenomes: the "Minimum Information about a Genome Sequence" (MIGS) specification. Nat Biotechnol 2008; 26:541-547.

PubMed doi:10.1038/nbt1360

7. Woese CR, Kandler O, Wheelis ML. Towards a natural system of organisms: proposal for the domains Archaea, Bacteria, and Eucarya. Proc Natl Acad Sci USA 1990; 87: 4576-4579.

PubMed doi:10.1073/pnas.87.12.4576

8. Garrity GM, Holt J. In:Garrity GM., Boone DR and Castenholz RW, eds. Taxonomic Outline of the Archaea and Bacteria. Bergey's Manual of Systematic Bacteriology, $2^{\text {nd }} E d$. Vol 1 The Archaea, Deeply Branching and Phototrophic Bacteria. 2001 pp. 155-166

9. Stackebrandt E, Rainey FA, Ward-Rainey NL. Proposal for a new hierarchic classification system, Actinobacteria classis nov. Int I Syst Bacteriol 1997; 47:479-491.

10. Wink JM. Compendium of Actinobacteria. http://www.gbif-prokarya.de/microorganisms/wink_pdf/DSM43017.pdf 2009.
11. Greiner-Mai E, Korn-Wendisch F, Kutzner HJ. Taxonomic revision of the genus Saccharomonospora and description of Saccharomonospora glauca sp. nov. Int / Syst Bacteriol 1988; 38:398405.

12. Küster E, Locci R. Studies on peat and peat microorganisms. I. Taxonomic studies on thermophilic Actinomycetes isolated from peat. Arch Microbiol 1963; 45:188-197.

13. Steger K, Jarvis $\AA$, Vasara T, Romantschuk M, Sundh I. Effects of differing temperature management on development of Actinobacteria populations during composting. Res Microbiol 2007; 158:617-624. PubMed doi:10.1016/j.resmic.2007.05.006

14. Webb MD, Ewbank G, Perkins J, McCarthy AJ. Metabolism of pentachlorophenol by Saccharomonospora viridis strains isolated from mushroom compost. Soil Biol Biochem 2001; 33:19031914. doi:10.1016/S0038-0717(01)00115-8

15. Anonymous. Biological Agents: Technical rules for biological agents www.baua.de TRBA 466.

16. Ashburner M, Ball CA, Blake JA, Botstein D, Butler H, Cherry JM, Davis AP, Dolinski K, Dwight SS, Eppig JT, et al. Gene ontology: tool for the unification of biology. Nat Genet 2000; 25:25-29. PubMed doi:10.1038/75556

17. Dees PM. WCG. Microbial diversity in hot synthetic compost as revealed by PCR-amplified rRNA sequences from cultivated isolates and extracted DNA. FEMS Microbiol Ecol 2001; 35:207216. PubMed doi:10.1111/j.15746941.2001.tb00805.x

18. Venter JC, Remington K, Heidelberg J, Halpern A, Rusch D, Eisen JA, Wu D, Paulsen I, Nelson KE, Nelson W, et al. Environmental genome shotgun sequencing of the Sargasso Sea. Science 2004; 304:66-74. PubMed doi:10.1126/science.1093857

19. Lee C, Grasso C, Sharlow MF. Multiple sequence alignment using partial order graphs. Bioinformatics 2002; 18:452-464.

PubMed doi:10.1093/bioinformatics/18.3.452

20. Castresana J. Selection of conserved blocks from multiple alignments for their use in phylogenetic analysis. Mol Biol Evol 2000; 17:540-552. PubMed

21. Stamatakis A, Hoover P, Rougemont J. A rapid bootstrap algorithm for the RAxML web-servers. 
Pati, et al.

Syst Biol 2008; 57:758-771.

PubMed doi:10.1080/10635150802429642

22. Liolios K, Mavromatis K, Tavernarakis N, Kyrpides NC. The Genomes OnLine Database (GOLD) in 2007: status of genomic and metagenomic projects and their associated metadata. Nucleic Acids Res 2008; 36:D475-D479.

PubMed doi:10.1093/nar/gkm884

23. Fogarty WM, Collins BS, Doyle EM, Kelly CT. The high maltose-forming eamylase of Saccharomonospora viridis: mechanisms of action. J Ind Microbiol Biotechnol 1993; 11:199-204.

24. Wu M, Hugenholtz P, Mavromatis K, Pukall R, Dalin E, Ivanova N, Kunin V, Goodwin L, Wu M, Tindall BJ, et al.. A phylogeny-driven genomic encyclopedia of Bacteria and Archaea. Nature (In press)

25. Sims D, Brettin T, Detter JC, Han C, Lapidus A, Copeland A, Glavina Del Rio T, Nolan M, Chen F, Lucas $\mathrm{S}$, et al. Complete genome sequence of $\mathrm{Ky}$ tococcus sedentarius type strain $\left(541^{\top}\right)$. SIGS 2009; 1:12-20.

26. Besemer J, Lomsadze A, Borodovsky M. GeneMarkS: a self-training method for prediction of gene starts in microbial genomes. Implications for finding sequence motifs in regulatory regions. Nucleic Acids Res 2001; 29:2607-2618. PubMed doi:10.1093/nar/29.12.2607

27. Markowitz VM, Mavromatis K, Ivanova NN, Chen IMA, Chu K, Kyrpides NC. Expert IMG ER: A system for microbial genome annotation expert review and curation. Bioinformatics 2009; 25:22712278.

PubMed doi:10.1093/bioinformatics/btp393

28. Pati A, Ivanova N, Mikhailova N, Ovchinikova G, Hooper SD, Lykidis A, Kyrpides NC. GenePRIMP: A Gene Prediction Improvement Pipeline for microbial genomes. (Submitted) 2009
29. Lowe TM, Eddy SR. tRNAscan-SE: a program for improved detection of transfer RNA genes in genomic sequence. Nucleic Acids Res 1997; 25:955-964. PubMed doi:10.1093/nar/25.5.955

30. Lagesen K, Hallin P, Rødland EA, Staerfeldt HH, Rognes T, Ussery DW. RNAmmer: consistent and rapid annotation of ribosomal RNA genes. Nucleic Acids Res 2007; 35:3100-3108. PubMed doi:10.1093/nar/gkm160

31. Griffiths-Jones S, Moxon S, Marshall M, Khanna A, Eddy SR, Bateman A. Rfam: annotating noncoding RNAs in complete genomes. Nucleic Acids Res 2005; 33:D121-D124. PubMed doi:10.1093/nar/gki081

32. Markowitz VM, Szeto E, Palaniappan K, Grechkin Y, Chu K, Chen IM, Dubchak I, Anderson I, Lykidis A, Mavromatis K, et al. The Integrated Microbial Genomes (IMG) system in 2007: data content and analysis tool extensions. Nucleic Acids Res 2008; 36:D528-D533. PubMed doi:10.1093/nar/gkm846

33. Karp PD, Paley SM, Romero P. The Pathway Tools Software. Bioinformatics 2002; 18:S225S232.

34. Caspi R, Foerster H, Fulcher CA, Kaipa P, Krummenacker M, Latendresse M, Paley SM, Rhee SY, Shearer A, Tissier B et al. The MetaCyc Database of metabolic pathways and enzymes and the BioCyc collection of pathway/Genome Databases. Nucleic Acids Res 2008; 36:D623-D631. PubMed

35. Karp PD, Ouzounis CA, Moore-Kochlacs C, Goldovsky L, Kaipa P, Ahren D, Tsoka S, Darzentas N, Kunin V, Lopez-Bigas N. Expansion of the BioCyc collection of pathway/genome databases to 160 genomes. Nucleic Acids Res 2005; 33:6083-6089. PubMed doi:10.1093/nar/gki892

36. List of growth media used at DSMZ: http://www.dsmz.de/microorganisms/media_list.p hp 